\title{
Maternal use of probiotics during pregnancy and effects on their offspring's health in an unselected population
}

\author{
Nicole Rutten ${ }^{1,2}$ - Anne Van der Gugten ${ }^{1}$ - Cuno Uiterwaal ${ }^{3}$ - Arine Vlieger $^{2}$ • \\ Ger Rijkers $^{4,5}$ - Kors Van der Ent ${ }^{1}$
}

Received: 2 June 2015 /Revised: 6 August 2015 / Accepted: 11 August 2015 / Published online: 30 August 2015

(C) The Author(s) 2015. This article is published with open access at Springerlink.com

\begin{abstract}
Probiotics are used by women in the perinatal period and may improve balance of microbiota, with possible health benefits for both mother and baby. Characteristics and (health) behaviour patterns of mothers using probiotics during pregnancy, and health effects on their offspring, were investigated. Differences between mothers using probiotics during pregnancy and those who did not, were assessed. In total, 341 out of 2491 (13.7\%) mothers reported use of probiotics during pregnancy. There were no significant differences in maternal features (gestation, age, ethnicity, education) between users and non-users. Logistic regression analyses showed that consumption of probiotics was significantly associated with use of homeopathic products [odds ratio (OR) 1.65, $95 \%$ confidence interval (CI) $1.17-2.33, p=0.005]$, maternal history of smoking (OR 1.72, $95 \%$ CI 1.25-2.37, $p=0.001$ ) and paternal history of smoking (OR 1.39, $95 \%$ CI 1.01-1.89, $p=$ $0.05)$. Common disease symptoms during the first year of life in the offspring did not differ between both groups.

Conclusion: The use of probiotics or other health-related products without doctor's prescription during pregnancy
\end{abstract}

Communicated by Peter de Winter

Nicole Rutten

n.b.m.m.rutten@umcutrecht.nl

Anne Van der Gugten

annevandergugten@hotmail.com

Cuno Uiterwaal

c.s.p.m.uiterwaal@umcutrecht.nl

Arine Vlieger

a.vlieger@antoniusziekenhuis.nl

Ger Rijkers

g.rijkers@ucr.nl

Kors Van der Ent

K.vanderEnt@umcutrecht.nl might point to compensation for types of less favourable behaviour. Probiotic use during pregnancy does not seem to induce positive health effects in the offspring in an unselected population.

What is Known:

- Aberrant microbiota compositions have been detected during critical periods when early programming occurs including pregnancy and early neonatal life.

- Probiotics modulate intestinal microbiota composition and are associated with positive health effects.

What is New:

- The use of probiotics or other health-related products without doctor's prescription during pregnancy is associated with and might point to compensation for types of less favourable behaviour.

- Probiotic use during pregnancy does not induce positive health effects in the offspring in this unselected population.

Keywords Probiotics $\cdot$ Behavioural patterns $\cdot$ Pregnancy Health effects

1 Department of Pediatric Pulmonology and Allergology, Wilhelmina Children's Hospital, University Medical Center Utrecht, Room KH.01.419.0, PO Box 85090, Utrecht 3508 AB, The Netherlands

2 Department of Pediatrics, St. Antonius Hospital, PO Box 2500, Nieuwegein 3430 EM, The Netherlands

3 Julius Center for Health Sciences and Primary Care, University Medical Center Utrecht, PO Box 85500, Utrecht 3508 GA, The Netherlands

4 Laboratory of Medical Microbiology and Immunology, St. Antonius Hospital, PO Box 2500, Nieuwegein 3430 EM, The Netherlands

5 Department of Sciences, University College Roosevelt, PO Box 94, Middelburg $4330 \mathrm{AB}$, The Netherlands 


\section{Abbreviations \\ ICPC International Classification of Primary Care WHISTLER Wheezing Illnesses Study Leidsche Rijn}

\section{Introduction}

Adequate nutrition is of major importance for one's health and well-being, especially during preconception and pregnancy $[3,5,17,18,21]$. Women become more aware of the health aspects of nutrition during pregnancy and seek for more nutrition-related information. Compared to the period before conception and pregnancy, pregnant women are more interested in healthy food and may be more receptive to behaviour change and lifestyle interventions $[2,26,32,33]$.

The increased nutrient requirements during pregnancy are mostly covered by a balanced diet, but dietary supplements are often taken to improve maternal or foetal health status [1]. Maternal (health) behaviour and micronutrient status during pregnancy have been linked to the health status of the child $[4,5,17,19,21]$. Moreover, aberrant microbiota compositions have been detected during critical periods when early programming occurs, including pregnancy and early neonatal life [17, 19, 25]. Manipulation of the maternal microbiota composition through the use of probiotics may have subsequent consequences for the health of the offspring, as the presence of bacteria in human milk implicates that modulation of maternal gut microbiota during pregnancy and lactation could have an effect on infant health $[10,13,14,23]$. Improvement of maternal intestinal microbiota composition, relief of possible gastrointestinal complaints, reduced infant's risk of developing atopic dermatitis, atopic sensitization and gastrointestinal symptoms as well as changes in foetal and infant's growth have been reported as positive health effects of probiotics [9, 12, 19, 22, 24]. In western societies, a substantial percentage of pregnant women appear to use probiotic supplements $[4,7]$. Because of the potential positive effects for the health of the woman and her neonate, pregnancy is an opportune time for probiotic use. Both beliefs and knowledge seem to strongly affect the mother's behaviour [6]. Review of the literature shows that ingestion of probiotics (combination of strains of Lactobacillus and Bifidobacterium) for a limited period of time during (late) pregnancy appears to be low risk, as it does not increase the rate of adverse pregnancy outcomes and seems to be well tolerated [30].

The aim of our study was to investigate characteristics and health behaviour patterns of mothers who use probiotics during pregnancy. As a secondary aim, we studied the effects of maternal use of probiotics on the offspring's health during the first year of life.

\section{Materials and methods}

\section{Study design and study population}

Subjects of the present study were mothers, with their child, participating in the ongoing Wheezing Illnesses Study Leidsche Rijn (WHISTLER) study. WHISTLER is a large prospective birth cohort study that started in December 2001 [15]. Baseline pre-pregnancy data of these parents were available from the Utrecht Health Project [11]. At the infant's age of 3-8 weeks, information on pre- and post-natal risk factors is obtained by questionnaires and the infant's birth weight and height, as well as gestational age and gender are recorded at an outpatient visit. Health parameters during the infant's first year of life are followed in the WHISTLER study through linkage with the computerized medical files recorded by general practitioners.

\section{Definitions of outcomes}

General characteristics and behaviour patterns of the mother (and father) were extracted from the WHISTLER database. History of smoking was defined as smoking ever, prior to pregnancy (without limitation in months/years ago). A positive history of parental allergy was defined as questionnairereported allergy to pollen, house dust mite, pets or food. Maternal higher education was defined as higher vocational or university education. Maternal paid occupation was defined as having a paid job (yes or no) at time of completing the questionnaire.

At the visit shortly after birth, maternal use of probiotics was asked as follows: Did you use probiotics during pregnancy, either as in a probiotic milk or yoghurt product and/ or probiotic-containing supplements? If yes, how many portions did you (on average) use per week? One portion was defined as use of one sachet or one capsule or use of one serving of a known probiotic-containing milk or yoghurt product. Active maternal smoking during pregnancy was considered present if the mother smoked at least one cigarette per day during pregnancy. Exposure to smoke during pregnancy was defined present when the mother smoked herself and/or if she reported being exposed to environmental cigarette smoke for at least $2 \mathrm{~h}$ per week. Use of supplements without doctor's prescription was defined as maternal-reported use of at least one of the following, during the past 3 months:

1. Vitamins, minerals, iron substitutes or resistanceincreasing substitutes;

2. Substitutes for other gastrointestinal complaints;

3. Substitutes against cough and cold;

4. Laxatives or sedatives. 
Use of homeopathic or herbal products during the past 3 months was also recorded.

Eating fruits and/or vegetables on a regular basis was considered as a parameter for a healthy lifestyle, and the variables were defined as eating five or more pieces of fruit a week and preparing fresh vegetables seven or more times a week.

To analyze the effects of the use of probiotics on the offspring's health, we used follow-up data from the WHISTLER study. In this study data on respiratory symptoms, disease episodes and day-care attendance are recorded during the first year of life using monthly questionnaires. Furthermore, GP diagnoses on upper respiratory tract infections, lower respiratory tract infections, gastrointestinal tract infections and constitutional eczema are recorded using International Classification of Primary Care (ICPC) codes.

\section{Analysis}

We compared mothers that used probiotics during pregnancy to non-users. In order to assess differences between groups, chi-square tests and independent samples $t$ tests were used where appropriate. For all the analyses, firstly, the univariable association with use of probiotics during pregnancy was estimated using logistic regression. Secondly, we extended to multivariable logistic regression to adjust for maternal characteristics or behaviour patterns that were significantly associated with use of probiotics or showed a trend towards significance in the univariable analysis. A cut-off $p$ value of $<0.30$ in the univariable association was used to insert variables into the multivariate model. Results are presented as odds ratios, with $95 \%$ confidence intervals and $p$ values. Associations were considered statistically significant if $p$ values were $\leq 0.05$. Analyses were run using SPSS version 20.0 (SPSS Inc., Chicago, IL, USA).

\section{Results}

Data of 2491 mothers were used for analysis of their lifestyle and behaviour during pregnancy. Group characteristics and maternal attitudes between mothers who did and did not use probiotics during pregnancy are shown in Table 1. Of the total group, $13.7 \%$ of the mothers reported use of probiotics during pregnancy. The mean usage per week was 3.5 portions (ranging from 1 to 15), in which there were no differences between the first and the second half of their pregnancy (data not shown). No differences were shown between both groups for gestational age, birth weight, maternal age at time of delivery, education and ethnicity of the mother. Probiotic-using mothers more often had a history of smoking, compared to non-users $(p=0.003)$. There was also a significant association between fathers with a history of smoking and the use of probiotics by the mother $(p=0.01)$. Maternal use of probiotics during pregnancy was significantly associated with use of other supplements and substitutes without doctor's prescription $(p=0.02)$ and the use of homeopathic products $(p<0.001)$.

Table 2 shows characteristics of the offspring of both probiotic-using and non-probiotic-using mothers. In the probiotic group, mothers more frequently gave birth to a boy ( $p=$ $0.04)$. Otherwise, no differences between the groups were demonstrated.

The results of the multivariable analysis on the association between the use of probiotics and other parental characteristics are shown in Table 3. The use of probiotics during pregnancy was increased in mothers who reported use of homeopathic substitutes or herbal medicines [odds ratio (OR) 1.65, $95 \%$ confidence interval (CI) 1.17-2.33, $p=0.005$ ]. Use of probiotics by the mother was also significantly associated with a higher frequency of history of smoking of both mother (OR $1.72,95 \%$ CI $1.25-2.37, p=0.001)$ and father (OR 1.39, $95 \%$ CI $1.01-1.89, p=0.05)$.

Table 4 shows the results of the multivariable analysis on the association of maternal use of probiotics during pregnancy and offspring's disease symptoms during the first year of life. These symptoms did not differ between infants from probiotic-using mothers and non-probiotic-using mothers in this population.

\section{Discussion}

This study shows that about one out of seven mothers in our population used probiotics during pregnancy. Use of probiotics during pregnancy was independently associated with use of homeopathic products and with a history of smoking of both mother and father.

To our knowledge, to date, no other studies analyzed the association between maternal use of probiotic supplements and other behaviour patterns during pregnancy. The number of mothers that reported consumption of probiotics during pregnancy in our cohort corresponds reasonably with previous estimates $[4,7]$. In our study, mothers that used probiotics during pregnancy were not characterized by specific maternal features (gestation, age, ethnicity, education) compared to mothers that did not use probiotics during pregnancy, although the literature shows that generally the adequacy of micronutrient intake during pregnancy is related to environmental, cultural and demographic variables $[4,5,16]$.

To many, probiotics, homeopathic products and nutritional and dietary supplements belong to the category of complementary medicines. Pregnancy is a time to become more aware of a healthy lifestyle including healthy nutrition. Taking any form of supplement may be part of such a (change in) lifestyle. We hypothesized that next to the health-promoting properties, that are suggested for probiotics, mothers may use 
Table 1 Characteristics of the study group

Parental characteristics

Maternal age at time of delivery (mean, in years) (SD)

Maternal weight (mean, in $\mathrm{kg}$ ) (SD)

Ethnicity mother (\% western)

Maternal higher education (\%)

Maternal paid occupation (\%)

Maternal history of smoking (prior to pregnancy ever) $(\%)$

Maternal smoking during pregnancy $(\%)$

Maternal smoke exposure during pregnancy (\%)

Current smoking mother (\%)

Paternal history of smoking (ever) (\%)

Current smoking father (\%)

Pet ownership during pregnancy (\%)

Use of alcohol (in general) (\%)

Use of substitutes/supplements without doctor's prescription during the past 3 months (\%) ${ }^{\mathrm{c}}$

Use of homeopathic substitutes/herbal medicines during the past 3 months (\%)

Use of fruits (5 or more pieces a week) (\%)

Use of fresh vegetables (7 or more times a week) (\%)

Maternal allergy $(\%)^{\mathrm{d}}$

Maternal allergy (\%)

Paternal allergy $(\%)^{\mathrm{e}}$

Children's day-care visit during the first 6 months of life (\%)

Total group Probiotic use Non-probiotic use $p$ value $n=2491 \quad(13.7 \%) \quad(86.3 \%)$

$\begin{array}{rrrr}32.7(3.9) & 32.8(3.7) & 32.7(4.0) & 0.63^{\mathrm{a}} \\ 71.4(12.5) & 70.2(12.4) & 71.5(12.3) & 0.12^{\mathrm{a}} \\ 89.9 & 91.0 & 89.7 & 0.51^{\mathrm{b}} \\ 67.3 & 70.0 & 66.9 & 0.31^{\mathrm{b}} \\ 89.8 & 89.9 & 89.8 & 0.99^{\mathrm{b}} \\ 35.4 & 43.3 & 34.1 & \mathbf{0 . 0 0 3}^{\mathrm{b}} \\ 6.2 & 7.0 & 6.1 & 0.51^{\mathrm{b}} \\ 14.9 & 17.0 & 14.5 & 0.23^{\mathrm{b}} \\ 8.2 & 9.8 & 7.9 & 0.30^{\mathrm{b}} \\ 40.6 & 48.3 & 39.4 & \mathbf{0 . 0 1}^{\mathrm{b}} \\ 17.5 & 16.5 & 17.7 & 0.64^{\mathrm{b}} \\ 39.3 & 41.6 & 38.9 & 0.34^{\mathrm{b}} \\ 79.6 & 81.2 & 79.4 & 0.50^{\mathrm{b}} \\ 75.9 & 81.5 & 75.0 & \mathbf{0 . 0 2}^{\mathrm{b}} \\ 22.3 & 30.5 & 20.9 & <\mathbf{0 . 0 0 1}^{\mathrm{b}} \\ 64.8 & 68.0 & 64.3 & 0.24^{\mathrm{b}} \\ 40.9 & 44.0 & 40.4 & 0.25^{\mathrm{b}} \\ 35.1 & 34.1 & 35.2 & 0.71^{\mathrm{b}} \\ 48.2 & 50.9 & 47.7 & 0.33^{\mathrm{b}} \\ 43.7 & 41.6 & 44.0 & 0.47^{\mathrm{b}} \\ 65.3 & 70.8 & 64.4 & \mathbf{0 . 0 3}^{\mathrm{b}} \\ & & & \end{array}$

$p$ values in bold are statistically significant

${ }^{\mathrm{a}} t$ test

${ }^{\mathrm{b}}$ Chi-square test

${ }^{c}$ e.g. vitamins, minerals, iron substitutes, resistance-increasing substitutes, substitutes for other gastrointestinal complaints, substitutes against cough and cold, laxatives and sedatives

${ }^{\mathrm{d}}$ Allergy to pollen, dust, house mite and pets

${ }^{\mathrm{e}}$ Allergy to pollen, dust, house mite, pets, food or other

Table 2 Characteristics of the study group

\begin{tabular}{|c|c|c|c|c|}
\hline Infant characteristics & $\begin{array}{l}\text { Total group } \\
n=2491\end{array}$ & $\begin{array}{l}\text { Probiotic use group } \\
(13.7 \%)\end{array}$ & $\begin{array}{l}\text { Non-probiotic use group } \\
(86.3 \%)\end{array}$ & $p$ value \\
\hline Gestational age (mean, in weeks) (SD) & $39.4(1.4)$ & $39.3(1.5)$ & $39.4(1.4)$ & $0.13^{\mathrm{a}}$ \\
\hline Birth weight (mean, in g) (SD) & $3526(514)$ & $3529(539)$ & $3525(510)$ & $0.87^{\mathrm{a}}$ \\
\hline Gender ( $\%$ boys within the group) & 49.3 & 54.5 & 48.5 & $0.04^{\mathrm{b}}$ \\
\hline Siblings (\% with at least one) & 54.0 & 50.9 & 54.5 & $0.22^{\mathrm{b}}$ \\
\hline Upper respiratory tract infections ${ }^{\mathrm{c}}(\%)$ & 46.9 & 46.6 & 47.0 & $0.88^{\mathrm{b}}$ \\
\hline Lower respiratory tract infections ${ }^{\mathrm{c}}(\%)$ & 9.0 & 11.0 & 8.6 & $0.15^{\mathrm{b}}$ \\
\hline Gastrointestinal tract infections ${ }^{\mathrm{c}}(\%)$ & 16.8 & 17.3 & 16.7 & $0.79^{\mathrm{b}}$ \\
\hline Constitutional eczema ${ }^{\mathrm{c}}(\%)$ & 12.9 & 14.3 & 12.7 & $0.39^{\mathrm{b}}$ \\
\hline
\end{tabular}

$p$ values in bold are statistically significant

${ }^{\mathrm{a}} t$ test

${ }^{\mathrm{b}}$ Chi-square test

${ }^{\mathrm{c}}$ During the first year of life, doctor's diagnosis 
Table 3 Associations between parental characteristics and use of probiotics during pregnancy

\begin{tabular}{|c|c|c|}
\hline & \multicolumn{2}{|c|}{ Multivariable analysis } \\
\hline & OR $(95 \% \mathrm{CI})$ & $p$ value \\
\hline Maternal history of smoking (prior to pregnancy ever) & $1.72(1.25-2.37)$ & 0.001 \\
\hline Maternal smoke exposure during pregnancy & $1.06(0.67-1.70)$ & 0.79 \\
\hline Use of substitutes/supplements without doctor's prescription during the past 3 months ${ }^{\mathrm{a}}$ & $1.05(0.70-1.58)$ & 0.82 \\
\hline Use of homeopathic substitutes/herbal medicines during the past 3 months & $1.65(1.17-2.33)$ & 0.005 \\
\hline Use of fruits ( 5 or more pieces a week) & $1.14(0.82-1.60)$ & 0.44 \\
\hline Use of fresh vegetables ( 7 or more times a week) & $0.96(0.70-1.32)$ & 0.81 \\
\hline Paternal history of smoking (ever) & $1.39(1.01-1.89)$ & 0.05 \\
\hline Maternal higher education & $1.27(0.88-1.83)$ & 0.20 \\
\hline Children's day-care visit during the first 6 months of life & $1.31(0.92-1.88)$ & 0.13 \\
\hline
\end{tabular}

$p$ values in bold are statistically significant

${ }^{\mathrm{a}}$ See Table 1 for definition

probiotics during pregnancy to compensate for adverse (prior) habits of themselves or their partners, for instance smoking.

We showed comparable disease symptoms during the first year of life in the offspring from probiotic-using and nonprobiotic-using mothers. Reviews and a meta-analysis demonstrated that current evidence on the effects of probiotics on the offspring's health is fairly inconclusive [8, 25, 27]. Our data do not add evidence for a beneficial effect.

The main strength of this study was the sample size which was large enough to estimate correlates of probiotic use during pregnancy. Our data have been prospectively documented, and all extensive parental characteristics and behaviour patterns could be aggregated from the database. Former studies of our group have demonstrated that the results may be generalized to other populations [28].

However, there are also some limitations. Use of supplements, and especially probiotics, may have been underreported due to non-recall or format of the questions, as has been reported in the literature [31]. Nevertheless, we cannot conceive that nonrecall of probiotic use would be related to use of other supplements or history of smoking and, therefore, is unlikely to have caused real bias.

Table 4 Associations between maternal use of probiotics during pregnancy and infant characteristics

\begin{tabular}{lll}
\hline & \multicolumn{2}{l}{ Multivariable analysis } \\
\cline { 2 - 3 } & OR $(95 \% \mathrm{CI})$ & $p$ value \\
\hline Upper respiratory tract infections $^{\mathrm{a}}$ & $0.97(0.77-1.22)$ & 0.79 \\
Lower respiratory tract infections $^{\mathrm{a}}$ & $1.31(0.90-1.91)$ & 0.16 \\
Gastrointestinal tract infections $^{\mathrm{a}}$ & $1.03(0.76-1.40)$ & 0.86 \\
Constitutional eczema $^{\mathrm{a}}$ & $1.15(0.82-1.60)$ & 0.42 \\
\hline
\end{tabular}

${ }^{\text {a }}$ During the first year of life, doctor's diagnosis
Also, neither the type of probiotic supplement nor the regularity of intake was specified and we were not able to investigate the use of probiotics by the mothers before and after pregnancy, which would have helped to discriminate mothers based on their using habits. There is emerging evidence that the effect of probiotics is strain specific and that timing, administration route and the applied dose do affect the outcomes. We consider the current reported conclusions valid and reliable because of the standardized manner of data collection, correction for potential confounders and presence of the unselected population. Moreover, we consider our population size sufficiently large to render our results statistically robust.

Thirdly, as reported earlier, in the study population of the Utrecht Health Project and WHISTLER study, a vast percentage of participants completed higher vocational or university education [20,29]. High socio-economic status and ethnicity might have played a role in parents' decision to participate, which results in a not entirely unselected study population. This effect will be mediated in the population but has to be taken into account when results are generalized to lower class (young) families.

\section{Conclusion}

This study shows that about one out of seven mothers in our population use probiotics during pregnancy. Probiotic-using mothers are not characterized by specific maternal features (gestation, age, ethnicity, education) compared to non-users. Use of probiotics during pregnancy is independently associated with use of homeopathic products and with parental history of smoking. According to common doctors' diagnosed disease symptoms in the offspring the first year of life, no differences between groups are observed. Using probiotics and/or other health-related products without doctor's prescription during pregnancy, for their health-promoting properties, might 
point to compensation for types of less favourable behaviour such as parental smoking. Caregivers and people concerned with pregnant women should be aware of this effect when discussing (nutritional) behaviour.

Acknowledgments We would like to thank all the parents and their children for their willingness to participate in the ongoing WHISTLER study and the Utrecht Health Project. The WHISTLER study is supported by grants from the Netherlands Organization for Health Research and Development (ZON-MW, no. 2001-1-1322), by the University Medical Center Utrecht, and by an unrestricted research grant from GlaxoSmithKline, The Netherlands. This part of the study was also partially funded by the Netherlands Enterprise Agency (Agentschap NL, nowadays RVO, grant number FND-06015).

Conflict of interest Kors van der Ent has received unrestricted research grants from Grünenthal and GlaxoSmithKline. The other authors declare that they have no conflicts of interest to disclose. The funding agencies did not have any role in the study design, data collection, analysis and interpretation of data, or in the writing of the article and the decision to submit it for publication.

\section{Compliance with ethical standards}

Ethical approval This study was approved by the medical ethics committee of the University Medical Center Utrecht, Utrecht, The Netherlands, and has, therefore, been performed in accordance with the ethical standards laid down in the 1964 Declaration of Helsinki and its later amendments.

Informed consent Written informed consent was obtained prior to inclusion in the study.

Authors' contribution NR designed research questions, analyzed data, wrote the paper and had primary responsibility for the final content. AG conducted research, analyzed data and wrote the paper. CU planned and set up the WHISTLER cohort and supervised statistical analysis. AV and GR designed research questions and critically reviewed the manuscript. KE designed research questions, planned and set up the WHISTLER cohort and supervised writing of the paper. All authors read and approved the final manuscript.

Open Access This article is distributed under the terms of the Creative Commons Attribution 4.0 International License (http:// creativecommons.org/licenses/by/4.0/), which permits unrestricted use, distribution, and reproduction in any medium, provided you give appropriate credit to the original author(s) and the source, provide a link to the Creative Commons license, and indicate if changes were made.

\section{References}

1. Arkkola T, Uusitalo U, Pietikäinen M et al (2006) Dietary intake and use of dietary supplements in relation to demographic variables among pregnant Finnish women. Br J Nutr 96:913-920. doi:10. 1017/BJN20061929

2. Artal R, Catanzaro RB, Gavard JA et al (2007) A lifestyle intervention of weight-gain restriction: diet and exercise in obese women with gestational diabetes mellitus. Appl Physiol Nutr Metab 32: 596-601. doi:10.1139/H07-024

3. Bayrampour H, Heaman M (2011) Comparison of demographic and obstetric characteristics of Canadian primiparous women of advanced maternal age and younger age. J Obstet Gynaecol Can 33:820-829

4. Bertelsen RJ, Brantsæter AL, Magnus MC, et al. (2013) Probiotic milk consumption in pregnancy and infancy and subsequent childhood allergic diseases. J Allergy Clin Immunol. doi: 10.1016/j.jaci. 2013.07.032

5. Berti C, Biesalski HK, Gärtner R et al (2011) Micronutrients in pregnancy: current knowledge and unresolved questions. Clin Nutr 30:689-701. doi:10.1016/j.clnu.2011.08.004

6. Bödecs T, Horváth B, Szilágyi E et al (2011) Association between health beliefs and health behavior in early pregnancy. Matern Child Health J 15:1316-1323. doi:10.1007/s10995-010-0698-0

7. Braun LA, Tiralongo E, Wilkinson JM et al (2010) Perceptions, use and attitudes of pharmacy customers on complementary medicines and pharmacy practice. BMC Complement Altern Med 10:38. doi: 10.1186/1472-6882-10-38

8. Doege K, Grajecki D, Zyriax B-C et al (2012) Impact of maternal supplementation with probiotics during pregnancy on atopic eczema in childhood — a meta-analysis. Br J Nutr 107:1-6. doi:10.1017/ S0007114511003400

9. Enomoto T, Sowa M, Nishimori K et al (2014) Effects of bifidobacterial supplementation to pregnant women and infants in the prevention of allergy development in infants and on fecal microbiota. Allergol Int 63:575-585. doi:10.2332/allergolint.13-OA0683

10. Fernández L, Langa S, Martín V et al (2013) The human milk microbiota: origin and potential roles in health and disease. Pharmacol Res 69:1-10. doi:10.1016/j.phrs.2012.09.001

11. Grobbee DE, Hoes AW, Verheij TJM et al (2005) The Utrecht Health Project: optimization of routine healthcare data for research. Eur J Epidemiol 20:285-287. doi:10.1007/s10654-004-5689-2

12. Hempel S, Newberry SJ, Maher AR et al (2012) Probiotics for the prevention and treatment of antibiotic-associated diarrhea: a systematic review and meta-analysis. JAMA 307:1959-1969. doi:10. 1001/jama.2012.3507

13. Huurre A, Laitinen K, Rautava S et al (2008) Impact of maternal atopy and probiotic supplementation during pregnancy on infant sensitization: a double-blind placebo-controlled study. Clin Exp Allergy 38:1342-1348. doi:10.1111/j.1365-2222.2008.03008.x

14. Jeurink PV, van Bergenhenegouwen J, Jiménez E et al (2013) Human milk: a source of more life than we imagine. Benef Microbes 4:17-30. doi:10.3920/BM2012.0040

15. Katier N, Uiterwaall CSPM, De Jong BM et al (2004) The Wheezing Illnesses Study Leidsche Rijn (WHISTLER): rationale and design. Eur J Epidemiol 19:895-903

16. Krzepota J, Putek-Szelag E (2014) Nutritional habits in the light of general health behaviours of pregnant women. Ann Agric Environ Med 21:425-428. doi:10.5604/1232-1966.1108618

17. Laitinen K, Collado MC, Isolauri E (2010) Early nutritional environment: focus on health effects of microbiota and probiotics. Benef Microbes 1:383-390. doi:10.3920/BM2010.0045

18. Laitinen K, Poussa T, Isolauri E (2009) Probiotics and dietary counselling contribute to glucose regulation during and after pregnancy: a randomised controlled trial. Br J Nutr 101:1679-1687. doi:10.1017/S0007114508111461

19. Luoto R, Laitinen K, Nermes M, Isolauri E (2010) Impact of maternal probiotic-supplemented dietary counselling on pregnancy outcome and prenatal and postnatal growth: a double-blind, placebo-controlled study. Br J Nutr 103:1792-1799. doi:10.1017/ S0007114509993898

20. Molenaar EA, van Ameijden EJC, Vergouwe Y et al (2010) Effect of nutritional counselling and nutritional plus exercise counselling in overweight adults: a randomized trial in multidisciplinary primary care practice. Fam Pract 27:143-150. doi:10.1093/fampra/cmp104

21. Nauta AJ, Ben Amor K, Knol J et al (2013) Relevance of pre- and postnatal nutrition to development and interplay between the 
microbiota and metabolic and immune systems. Am J Clin Nutr 98: 586S-593S. doi:10.3945/ajcn.112.039644

22. Niers L, Martín R, Rijkers G et al (2009) The effects of selected probiotic strains on the development of eczema (the PandA study). Allergy 64:1349-1358. doi:10.1111/j.1398-9995.2009.02021.x

23. Perez PF, Doré J, Leclerc $M$ et al (2007) Bacterial imprinting of the neonatal immune system: lessons from maternal cells? Pediatrics 119:e724-e732. doi:10.1542/peds.2006-1649

24. Rautava S, Kainonen E, Salminen S, Isolauri E (2012) Maternal probiotic supplementation during pregnancy and breast-feeding reduces the risk of eczema in the infant. J Allergy Clin Immunol 130: 1355-1360. doi:10.1016/j.jaci.2012.09.003

25. Sanz Y (2011) Gut microbiota and probiotics in maternal and infant health. Am J Clin Nutr 94:2000S-2005S. doi:10.3945/ajcn.110. 001172

26. Szwajcer EM, Hiddink GJ, Koelen MA, van Woerkum CMJ (2007) Nutrition awareness and pregnancy: implications for the life course perspective. Eur J Obstet Gynecol Reprod Biol 135:58-64. doi:10. 1016/j.ejogrb.2006.11.012

27. Thum C, Cookson AL, Otter DE et al (2012) Can nutritional modulation of maternal intestinal microbiota influence the development of the infant gastrointestinal tract? J Nutr 142:1921-1928. doi:10. 3945/jn.112.166231
28. Van der Gugten AC, Koopman M, Evelein AMV et al (2012) Rapid early weight gain is associated with wheeze and reduced lung function in childhood. Eur Respir J 39:403-410. doi:10.1183/ 09031936.00188310

29. Van Putte-Katier N, van der Gugten AC, Uiterwaal CSPM et al (2012) Early life lung function and respiratory outcome in the first year of life. Eur Respir J 40:198-205. doi:10.1183/09031936.00175910

30. VandeVusse L, Hanson L, Safdar N (2013) Perinatal outcomes of prenatal probiotic and prebiotic administration: an integrative review. J Perinat Neonatal Nurs 27:288-301. doi:10.1097/JPN. 0b013e3182a1e15d, quiz E1-2

31. Wehby GL, Castilla EE, Lopez-Camelo JS, Murray JC (2009) Predictors of multivitamin use during pregnancy in Brazil. Int J Public Health 54:78-87. doi:10.1007/s00038009-8103-8

32. Weir Z, Bush J, Robson SC et al (2010) Physical activity in pregnancy: a qualitative study of the beliefs of overweight and obese pregnant women. BMC Pregnancy Childbirth 10:18. doi:10.1186/ 1471-2393-10-18

33. Wulandari LPL, Klinken Whelan A (2011) Beliefs, attitudes and behaviours of pregnant women in Bali. Midwifery 27:867-871. doi:10.1016/j.midw.2010.09.005 